\title{
EURÍPIDES: SUPLICANTES (838-954)
}

\author{
Evandro Luis Salvador* \\ Universidade Estadual Paulista Júlio de Mesquita Filho
}

\begin{abstract}
This text presents a free verse translation of the funeral rites (838-954) in Euripides' The Suppliant Women. It is followed by a panoramic introduction highlighting the social function of the funeral for the war-dead. In this tragedy, Theseus fulfills the role of a commander and buries the majority of the Argive dead at Eleutherai, and it is Adrastus, along with Theseus, who conducts the funeral rites for the other five Argive heroes at Eleusis.

KEYWORDS: Tragedy; The Suppliant Women; Euripides; Funeral Rites; Adrastus.
\end{abstract}

quarto episódio da tragédia euripidiana As Suplicantes contém o que se convencionou denominar de ritos fúnebres ou discursos de epitáfios. As mães dos guerreiros argivos mortos na expedição contra Tebas, acompanhadas de Adrasto, líder daquela expedição militar, recorrem a Atenas com o intuito de recuperar os cadáveres retidos nas cercanias de Tebas, pois Creonte, após a morte de Eteócles, proibira o resgate dos restos mortais, naquilo que se constituia uma afronta à lei pan-helênica referente ao sepultamento. Depois de um longo processo, Teseu aceita a tarefa, declara guerra a Tebas, resgata os corpos e os conduz a Elêusis, onde todos (as mães, Adrasto e os filhos dos heróis mortos) estavam à espera do retorno do rei de Atenas. O início do quarto episódio começa com o mote criado por Teseu: quem são e de onde vieram os heróis argivos que lutaram na expedição d'Os Sete contra Tebas? Cabe a Adrasto, então,

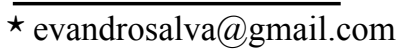


tecer os discursos fúnebres. No entanto, vale lembrar que somente cinco cadáveres estão expostos na orquestra e é a eles que Adrasto dirige seu elogio: Capaneu, Etéoclo, Hipomedonte, Partenopeu e Tideu. Os outros dois, Anfiarau e Polinices, não estão presentes: o primeiro foi sorvido durante a batalha, junto com sua quadriga, para os confins da terra, e o segundo, hipoteticamente, está enterrado em Tebas. A esses dois Teseu destina poucas, mas elogiosas palavras.

Há dois ecos fortíssimos nessa passagem. O primeiro é relativamente contemporâneo a Eurípides e tem um aspecto formal: a oração fúnebre de Péricles, pronunciada para homenagear os combatentes mortos no primeiro ano da Guerra do Peloponeso. O segundo é mais antigo, mas nem por isso menos intenso, e tem um aspecto intertextual: a cena central da tragédia Os Sete contra Tebas, de Ésquilo, que conquistou o primeiro lugar nas Dionísias de 467 a.C.

Quanto à forma dos discursos de epitáfios, eles fazem parte de um ritual que encerra alguns aspectos, pois através deles somos conduzidos into another world, a private and personal one ${ }^{1}$ devido aos assuntos comezinhos que cercam os elogios de cada herói. Portanto, estão circunscritos à esfera doméstica e particular. ${ }^{2}$ Contudo, têm projeção coletiva porque são um evento público formal. ${ }^{3}$ De acordo com Whitehorne, ${ }^{4}$ as orações fúnebres eram pronunciadas por oradores em funerais públicos, o que se aplica neste caso, na medida em que há dois exércitos (argivo e ateniense) presentes, os elogios são feitos por dois reis (Adrasto e Teseu) e o coro dos epígonos faz a projeção da vingança como um fecho de temática militar. Michelini ${ }^{5}$

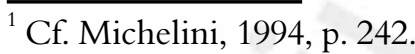

${ }^{2} \mathrm{Na}$ esfera doméstica, o procedimento dos rituais fúnebres estava circunscrito à esfera feminina. O thrênos das mulheres exercia especificamente esse papel. Para esse assunto, cf. Fishman (2008, p. 267-295), Toher (2001, p. 332-343) e Segal (1993).

${ }^{3}$ Toher (2001, p. 333) afirma que a cerimônia fúnebre, como evento público, "remained a unique Athenian practice until the mid-fourth century B.C." e, citando Pritchett (1985), sustenta "that burial of the dead on the battlefield was the universal practice of Greek hoplites before the institution of the Athenian public funeral in the early fifth century B.C.”. Danes (2011, p. 18) sustenta que as orações fúnebres contribuíam para a autoimagem de Atenas: "That this ideal was dear to the Athenians is obvious in both the public speeches of the fifth and fourth centuries and funeral speeches. We can mention Lysias, Isocrates, Demosthenes, Hypereides and Thucydides, among others".

${ }^{4}$ Cf. Whitehorne, 1996, p. 67-68.

${ }^{5}$ Cf. Michelini, 1994, p. 242. 
vai na mesma direção quando afirma que "it is appropriate that Suppliants, a remarkably public play, should include a funeral speech, another public and formal event". Essa é uma lacuna preenchida, conforme Segal, ${ }^{6}$ pois "tragedy has a dialectical structure lacking in civic ritual or in such monologic forms of civic discourse as the epitaphios, or funeral speech". Como forma de discurso e representação cívicas, a tragédia corrige sua rota ao acomodar "the explicit statements of civic ideals (and ideologies) in epideitic oratory or funeral eulogy", fazendo com que As Suplicantes operem num plano ideológico altamente abrangente, refletindo os mais variados aspectos e temas da convivência pública e privada.

Adrasto, que vinha paulatinamente sofrendo uma corrosão de sua imagem enquanto hábil orador e havia se apresentado como uma figura desprezível por conta dos efeitos nefastos que sua guerra produziu, agora recobra o esplendor de sua verve retórica, porque a seu cargo ficam os elogios aos mortos, ou seja, ele torna-se o orador oficial de um ritual familiar e coletivo. Ao oferecer a palavra a Adrasto, Teseu confere a ele o direito de falar "about the values of the community and about the meaning and values of human life in general".

O conteúdo dos discursos de epitáfios segue essa diretriz. O que chama a atenção neles, em primeiro lugar, é que há uma clara alusão à cena central da tragédia Os Sete contra Tebas de Ésquilo, situação que parece não sair da mira de Eurípides, mesmo após quase meio século de sua dramatização. Nessa cena de Ésquilo, um mensageiro nomeia os seis primeiros argivos que atacarão as seis primeiras portas da cidade, bem como caracteriza o modo como eles se apresentam no clangor do préataque. Todos eles, sem exceção, são descritos como arrogantes, violentos e prepotentes. Em segundo lugar, destaque-se que a cena em Eurípides começa com a recusa de Teseu em aceitar narrativas de cunho heroico, nas quais os feitos e a performance dos heróis são postos em relevo. Teseu pede a Adrasto que relate a origem dos heróis mortos, pois a audácia que eles demonstraram na expedição contra Tebas é digna de nota, mas, ao mesmo tempo, ressalva que ele deve evitar a narrativa enfadonha dos duelos singulares. Em terceiro lugar, verifica-se que os discursos fúnebres são a tentativa de desfazer a imagem de jovens temerários e audaciosos construída no primeiro episódio, desvinculando completamente a ideia de que eles, impetuosos na guerra, procediam insolentemente na vida cotidiana, como

\footnotetext{
${ }^{6}$ Cf. Segal, 1993 , p. 5.

${ }^{7}$ Cf. Segal, 1993, p. 5.

${ }^{8}$ Cf. Segal, 1993, p. 5.
} 
se a hýbris se espraiasse por todos os setores de suas vidas. Neste ponto, há uma crítica de Adrasto a Teseu, pois "the virtue displayed by Kapaneus in his wealth and by Eteoklos in his poverty belie the greed that Theseus saw as the force behind disturbed internal class relations and belligerent external activities".

Há quem leia os ritos fúnebres como uma refinada ironia ou sátira de Eurípides. Storey ${ }^{10}$ recupera o tom geral dos que leem a passagem sarcasticamente ao dizer o seguinte: "These young men whose desire and clamour for war has ruined themselves, their families, and their citizens are ironically presented as champions of the very institutions that they have ruined". O estilo de vida dos chefes argivos é marcado por virtudes nos mais amplos setores, conquanto eles tenham trazido sofrimentos para mulheres, crianças e cidades envolvidas na guerra. Esse contraste permite uma leitura irônica. Contudo, devo oferecer um contraponto, pois entendo que o propósito de mostrar a questão sob outro ângulo é justamente realçar

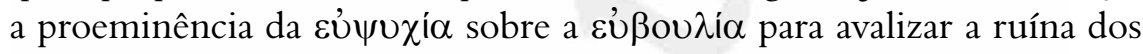
jovens. O que teria contribuíùdo para operar a transformação de jovens exemplares em guerreiros destemperados?

Parece que o propósito de se mostrar a vida de virtude antes da guerra é que a irreflexão e a sanha pela glória podem conduzir à desgraça e acabar com uma vida esmerada e exemplar. E isso, a vida, como Adrasto disse nos versos 953-954, não se recupera jamais. Há muito em jogo quando se vai para a guerra e, considerando que a tragédia foi representada no período de uma guerra de grandes proporções, essa cena é uma clara advertência ao ímpeto juvenil.

Essa nossa interpretação é amparada pelo que diz Teseu nos versos 843, quando o rei de Atenas identifica os ouvintes da narrativa de Adrasto:

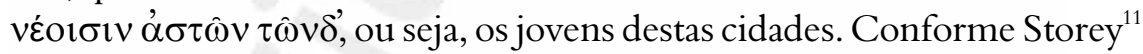
" "citizens' (astô) is an odd term to use of Argives in a foreign land" e, tendo em vista o uso do plural pelo singular, resta-nos que a cidade referida por Teseu é Atenas. Indo além, trata-se dos jovens órfãos da guerra que a cidade homenageava por ocasião das Dionísias. É, portanto, uma ocorrência metateatral e, nesse sentido, a narrativa tem função paidêutica. Numa tragédia que tem insistido na diplomacia como instância possível, em que o lógos é usado em abundância, em que acompanhamos a negociação verbal entre Teseu e o arauto tebano para evitar uma guerra, fica claro

\footnotetext{
${ }^{9}$ Cf. Michelini, 1994, p. 244

${ }^{10}$ Cf. Storey, 2008, p. 67-70.

${ }^{11}$ Cf. Storey, 2008, p. 64.
} 
que a ponte entre a vida abundante em virtudes morais e cívicas dos heróis argivos e a audácia e fúria com que eles se dedicaram à expedição é a supressão completa da instância representada pelo lógos. Mesmo que Teseu seja um contraexemplo por ter recorrido à força para solucionar o problema do resgate dos corpos, é inegável que o intrumento bélico foi usado como o último recurso, quando todas as instâncias de diálogo foram esgotadas. Diante da intransigência do tirano de Tebas, que estava presente no momento premente da guerra pelo resgate dos corpos e nada fez para afastá-la de sua cidade, o uso do recurso militar se fez necessário. Por isso, discordo da ideia segundo a qual Eurípides estaria trabalhando com ironia.

Pelo alto relevo e distinção que os rituais fúnebres representam podemos, enfim, entender o motivo pelo qual o pedido do coro e de Adrasto já no prólogo não se restringiu apenas ao ato do resgate dos cadáveres. As exéquias são uma forma de desfazer a atmosfera de desgraça e desonra que pairava sobre eles no episódio do malogro da guerra e da suspensão do enterro ao mesmo tempo em que funcionam como um catalisador das emoções dos parentes. Conforme Toher:

[...] in general funeral ritual serves a social function that enables traumatized survivors to recover from their grief and disorientation and resume normal social roles. Funeral ritual resolves death's trauma by allowing the expression and alleviation of grief through mourning $[\ldots]^{12}$

Nada mais adequado do que pedir a Atenas a consecução do ritual público, pois esse evento é típico da cidade ática. Mas, conforme Segal, ${ }^{13}$ os sentimentos que seriam reprimidos numa austera cerimonia oficial, como a oração fúnebre de Péricles, podem aparecer mais relaxados na tragédia grega, liberando as sentimentalidades das amarras do decoro público.

A tradução que se segue é em verso livre. Usamos o texto grego da edição de James Diggle (1981). Consultamos outras edições com particular interesse nos comentários, tais como a italiana de Ammendola (1922) e a inglesa editada por Paley (2010); consultamos as traduções de Coleridge (1938), Grégoire (1976) e Ferreira (2012). Algumas indicações cênicas, extraídas do contexto, acompanham a tradução para facilitar a compreensão do gestual dos personagens.

Teseu (Dirigindo-se ao corifeu)

Pretendia fazer-te perguntas $†$ enquanto te esgotavas

\footnotetext{
${ }^{12}$ Cf. Toher, 2001, p. 336.

${ }^{13}$ Cf. Segal, 1993, p. 20.
} 
em lamentos para o exército, mas desisti †; depondo, aqui, os mortos, permitias lamúrias; mas agora,Adrasto,

indago: (A Adrasto) de que linhagem procedem estes distintos e corajosos varões? Dize, enquanto mais sensato, para os jovens desta cidade: pois és experiente.

Pois eu vi que a ousadia deles é mais poderosa do que usar de palavras, com a qual esperavam saquear Tebas.

Só não perguntarei uma coisa para não ser motivo de riso:

com quem cada um deles se encontrou na refrega

ou de qual inimigo cada um recebeu o golpe da lança. ${ }^{14}$

Essas informações são inúteis para os ouvintes

e para ofalante; aquele que passou pela batalha,

após ter visto uma nuvem de dardos diante dos olhos,

claramente tenta reportar quem foi valente.

Não seria capaz de investigar tais detalhes, muito menos de acreditar nos que ousam reportá-los.

Pois apenas alguém que está diante de seu inimigo

pode ser capaz de observar suas próprias demandas.

\section{Adrasto}

Então agora ouve: pois a mim me agrada a oportunidade de louvar os companheiros; dos quais ao menos eu quero falar verdadeira e justamente. Vês o impetuoso, fulminado pelo projétil?

É Capaneu, para quem a vida era intensa, mas sem se jactar de sua prosperidade.

Não se pensava maior do que um indigente, evitava aquele que se gabava de seus banquetes e depreciava a frugalidade: ele dizia que entupir o ventre não é benéfico, mas sim ter o necessário.

Era um amigo leal aos amigos, estivessem eles presentes ou não: não contava muitos deles.

Seu caráter era verdadeiro, de fino trato nas palavras, não dirigindo violência nem aos escravos

\footnotetext{
${ }^{14}$ É uma clara alusão à tragédia Os Sete contra Tebas, de Ésquilo, especificamente ao diálogo central em que Etéocles contrapõe cada guerreiro tebano àquele guerreiro argivo mencionado pelo mensageiro. Na tragédia As Fenícias, de Eurípides, aparece esse mesmo procedimento de se furtar a detalhar nomes de guerreiros nos versos

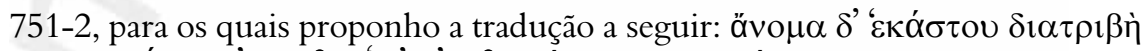

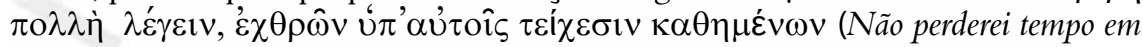
dizer seus respectivos nomes / pois os inimigos estão estacionados diante das fortificações). $\mathrm{O}$ procedimento não é somente enfadonho, mas risível, de acordo com Eurípides.
} 
e nem aos cidadãos. Refiro-me agora ao segundo, Etéoclo, talhado numa outra espécie de virtude.

Embora sendo jovem e carente de posses, tinha enormes honras na terra argiva.

Aindaquemuitasvezesosamigos lheoferecessemouro,

não permitia que adentrasse sua casa, pois queria evitar que suas maneiras fossem escravizadas pelas riquezas.

Odiava os desvairados, não a cidade,

pois ela não era responsável por sua má fama

se o seu condutor era um pilantra.

O terceiro deles, Hipomedonte, teve tal natureza:

já na infância empenhava seu ímpeto não aos prazeres

das Musas, de uma vida molenga,

mas estava no campo se comprazendo em cultivar

a virilidade de sua natureza vigorosamente;

indo para a caça, alegrando-se com os corcéis, envergando

o arco nas mãos, queria dar à cidade um corpo eficiente.

O outro é filho de Atalanta, a caçadora,

o menino Partenopeu, de uma beleza extraordinária;

era Árcade, mas quando veio à corrente do Ínaco

foi educado segundo os costumes argivos.

Enquanto era educado lá — como era necessário aos metecos -

não foi problemático para a cidade, nem motivo de inveja

e nem contumaz palrador, razão pela qual

cidadãoe estrangeiroseriam excessivamente opressivos.

Habituado ao exército, defendia sua terra como

se fosse de Argos, alegrava-se quando a cidade

vencia e se entristecia quando saía derrotada.

Embora tivesse muitos amantes e $†$ tantas $†$ mulheres,

ele se preocupava em não cometer qualquer deslize.

Quanto a Tideu, farei um enorme elogio em breves palavras:

[não era brilhante com as palavras, mas na batalha

era um talentoso artífice para inventar muitas e sábias soluções.

No intelecto, afastava-se do irmão Meleagro,

mas adquiriu reputação idêntica na arte da lança,

descobrindo a arte exata no manuseio das armas.]

Tinha um caráter ambicioso ao extremo, e sua coragem

era similar nos trabalhos, mas não nos discursos.

Não te estranhes, Teseu, pelos discursos proferidos

em relação aos homens que ousaram morrer diante das torres.

Pois o ser bem-educado não traduz um respeito com reservas;

qualquer homem que tenha se esmerado em atos de valor

envergonha-se de ser considerado vil. A coragem é

ensinável, já que também uma criança aprende

a falare a ouvir aquilo de que não tem conhecimento. 
E aquilo que alguém assimila, isso será mantido até a velhice: sendo assim, fornecei uma boa educação às crianças.

\section{Coro}

Ó, filho, infeliz

eduquei a ti ${ }^{15}$ levei no ventre

suportando o trabalho entre dores: e

agora Hades tem o fruto

de meu trabalho, desgraçada,

e eu não tenho quem me ampare na velhice,

esta infeliz geratriz de um filho!

\section{Teseu}

Então o nobre filho de Ecleu ${ }^{16}$

os deuses, tendo tragado vivo para as entranhas

da terra, com sua quadriga, manifestamente elogiam.

Após elogiarmos o filho de Édipo, menciono Polinices, no que não estaríamos incorrendo em inverdades.

Pois ele era meu hóspede antes de, voluntariamente, partir em fuga para Argos, deixando a cidade do pai.

Mas sabes o que quero que faças em relação a eles?

Ad. Nada sei, a não ser obedecer tuas palavras.

Te. A Capaneu, abatido pelo fogo de Zeus...

Ad.Desejas que enterre comocadáver sacro, separadamente?

Te. Sim: e a todos os outros em uma só pira.

Ad. E onde porá a tumba dele separando-a dos outros?

Te. Construirei a tumba dele junto deste templo.

Ad. Os escravos poderiam se encarregar de tal trabalho.

Te.Eestes para nós: que venha o peso dos cadáveres!

Ad. (Ao coro) Vinde, ó mães infelizes, junto dos filhos!

Te. Isso que dizes não é conveniente, Adrasto.

Ad. Como? As mães não necessitam tocar os filhos?

Te. Elas poderiam morrer quando os vissem desfigurados.

Ad. Sim, as feridas e o sangue dos corpos são uma visão amarga.

Te. Por que, então, queres adicionar dor a elas?

\section{Adrasto}

Venceste. (Para as mães) É necessário esperar pacientemente, pois Teseu tem razão. Quando pusermos fogo neles

\footnotetext{
${ }^{15}$ É muito comum as odes corais apresentarem assíndetos. Ao invés de repetir o mesmo

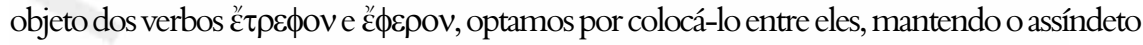
na tradução.

${ }^{16}$ Anfiarau, o adivinho.
} 
podereis recolher os ossos. Ó miseráveis mortais, por que ostentais armas e mutilais uns aos outros?

Cessai e, mantendo-se distante dos distúrbios, guardai a paz mútua entre as cidades.

Breve coisa é a vida: é necessário percorrê-la mais tranquilamente e não com aflições.

\section{Referências}

DANES, J. The political thought of the Suppliant Women. Graeco-Latina Brunensia, Brno, vol. 16, p. 17-30, 2011.

DIGGLE, J. EVRIPIDES: FABVLAE. New York: Oxford University Press, 1981. EURIPIDES. Supplices. Edited by F. Paley. Cambridge: Cambridge University Press, 2010 (vol. 1).

EURIPIDES. The Suppliants. Trad. E. P. Coleridge. Adelaide: The University of Adelaide Library, 2014.

EURIPIDE. Le Supplici. Commentate da Giuseppe Ammendola. Palermo: Remo Sandron, 1922.

FERREIRA, J. R. Eurípides: as Suplicantes. Porto Alegre: Movimento, 2012.

FERREIRA, J. R. Aspectos políticos nas "Suplicantes" de Eurípides. Humanitas, Coimbra, vol. 37-38, p. 82-121, 1986.

FISHMAN, A. "Thrênoi to Moirológia": female voices of solitude, resistance and solidarity. Oral Tradition, Columbia, vol. 23, p. 267-295, 2008.

KOVACS, D. Euripides. Cambridge: University Press, 1998 (vol. 3).

MICHELINI, A. N. Political themes in Euripides' Suppliants. The American journal of philology, Baltimore, vol. 115, n 2, p. 219-252, 1994.

PARMENTIER, L.; GRÉGOIRE, H. Euripide: Héraclès; Les suppliantes; Ion. Paris: Les Belles Lettres, 1976.

PRITCHETT, W. K. The Greek state at war. Berkeley/ Los Angeles: University of California Press, 1985, p. 249-251 (vol. IV).

SEGAL, C. Euripides and the poetics of sorrow. Durham: Duke University Press, 1993. STOREY, I. C. Euripides: Suppliant Women. London: Duckworth, 2008.

TOHER, M. Euripides' "Supplices" and the social function of funeral ritual. Hermes, Stuttgart, vol. 129, p. 332-343, 2001.

WARREN, R.; SCULLY, S. Euripides: Suppliant Women. Oxford: Oxford University Press, 1995.

WHITEHORNE, J. E. G. The dead as spectacle in Euripides' "Bacchae" and "Supplices". Hermes, Stuttgart, p. 59-72, 1986. 